\title{
Molecular Diseases
}

\author{
With Particular Reference to the Hemoglobinopathies*
}

\author{
Yuichi Yamamura, M D \\ Professor of the Third Department of Internal Medicine \\ Medical School, Osaka University
}

Molecular diseases are defined here as the disorders caused by abnormality in the primary structure or amino-acid sequence of a protein in the living body. The concept of molecular disease has been established by a number of studies on structure and function of abnormal hemoglobins and on pathophysiology of the hemoglobinopathies. The hemoglobinopathy is regarded as the most excellent model of molecular diseases.

This article describes molecular pathology and genetics of the hemoglobinopathies some of which have been strenuously studied in our laboratory for these over ten years, and discusses the application of knowledges obtained to other inborn errors of metabolism and further the biochemical distinctiveness of the individuals.

Hemoglobin is a heme protein packed in the red cells, the main function of which is to transport oxygen to the tissue. Each molecule consists of four polypeptide chains, two different chains with a heme group. Hemoglobin $\mathrm{A}$, the normal adult hemoglobin, is designated $\alpha_{2}{ }^{\mathrm{A}} \beta_{2}{ }^{\mathrm{A}}$. The $\alpha$-chain consists of 141 amino acids and the $\beta$-chain has 146. The advance in knowledge of the three-dimensional structure of the hemoglobin molecule based on an X-ray analysis has opened the possibility of studying mole-

\footnotetext{
* Presented at the 73rd Annual Meeting of the Japanese Society of Internal Medicine, May 28, 1976, in Sendai.
}

cular pathology of hemoglobin.

The hemoglobinopathies are defined as the diseases caused by inherited structural abnormality of the protein part, globin, of hemoglobin and are clinically classified as follows :

1. Sickle cell disease. Sickle cell disease was the first hemoglobinopathy to be designated as the molecular disease. It is a severe hemolytic disorder caused by the homozygous occurrence of hemoglobin $\mathrm{S}$, $\alpha_{2}{ }^{\mathrm{A}} \beta_{2}{ }^{6 \mathrm{Glu} \rightarrow \mathrm{Val}}$, which aggregates in deoxy form and decreases in solubility, forming the sickle type red cell.

2. Hemoglobin $M$ disease. Hemoglobin $\mathrm{M}$ disease is characterized by cyanosis and, in some types, mild hemolytic anemia.

Of the five described types of hemoglobin $M$ shown in Table 1 , four were found in Japan. In each of them, one of the two histidines in contact with the heme group in either $\alpha$ - or $\beta$-chain is replaced by tyro-

Table 1. Classification and characteristics of hemoglobin $\mathrm{M}$ diseases.

\begin{tabular}{|c|c|c|c|c|c|}
\hline Designation & $\begin{array}{l}\text { Position in } \\
\text { molecule }\end{array}$ & $\begin{array}{l}\text { Residue } \\
\text { number }\end{array}$ & Replacement & Cyanosis & $\begin{array}{l}\text { Conpensated } \\
\text { hemolytic anemi }\end{array}$ \\
\hline M Iwate & heme & a 87 & $\mathrm{His}+\mathrm{Tyr}$ & definite & absent \\
\hline $\begin{array}{l}\text { M Boston } \\
\text { (Osaka) }\end{array}$ & heme & $\alpha 58$ & $\mathrm{His} \rightarrow \mathrm{Tyr}$ & definite & absent \\
\hline $\begin{array}{l}\text { M Hyde Park } \\
\text { (Akita) }\end{array}$ & heme & B 92 & $\mathrm{His}+\mathrm{Tyr}$ & $\begin{array}{l}\text { less } \\
\text { definite }\end{array}$ & present \\
\hline $\begin{array}{l}\text { M Saskaton } \\
\text { (Kurume) }\end{array}$ & heme & B 63 & $\mathrm{His} \rightarrow \mathrm{Tyr}$ & $\begin{array}{l}\text { less } \\
\text { definite }\end{array}$ & present \\
\hline M M11waukee & heme & B 67 & $\mathrm{Va} 1 \rightarrow \mathrm{Glu}$ & definite & absent \\
\hline
\end{tabular}


sine, and the tyrosine forms a stable internal complex with the heme iron in the ferric state.

We had the opportunities to study on the physicochemical properties of all five variants. It was particularly interesting that the electron paramagnetic resonance (EPR) spectra of hemoglobins $M$ revealed remarkable abnormality. As illustrated in Fig. 1, there were distinct differences among hemoglobins $M$, and the shape of the curves were characteristic of each one. We recommend the use of EPR as a simple and accurate method for the identification of hemoglobins $\mathrm{M}$.

Studies on oxygen equilibrium of normal chains in hemoglobins $M$ demonstrated that cyanosis seen in hemoglobin $\mathbf{M}_{\text {Boston }}$ and

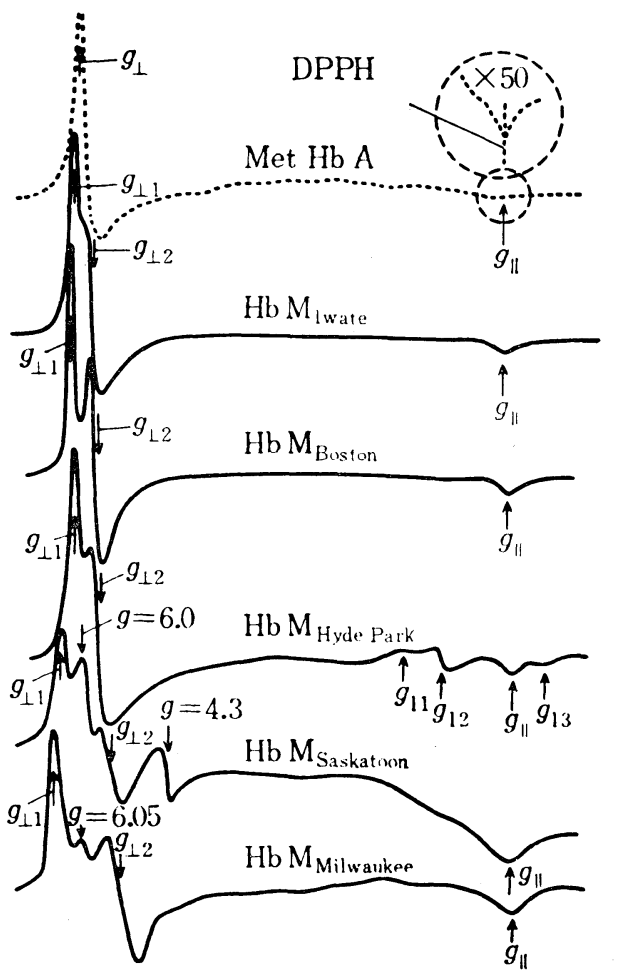

Fig. 1. Electron paramagnetic resonance (EPR) spectra of patients' blood of hemoglobin M Iwate, M Boston, M Myde Park, $\mathbf{M}_{\text {Saskatoon and }}$ MMilwaukee.

EPR spectrum of methemoglobin $A$ is also shown for comparison. DPPH, diphenyl-picrylhydrazyl.
$M_{\text {Iwate }}$ diseases was due to the increased deoxyhemoglobin as well as methemoglobinemia.

3. Unstable hemoglobin diseases. The unstable hemoglobins are one cause of the congential nonspherocytic hemolytic anemias with Heinz body. The clinical picture varies from variants to variants, some having almost no symptoms, whilst in others the degree of hemolysis is much more severe, accompanied by the urinary dipyrrole excretion.

The instability of the hemoglobin is due to amino acid deletion, substitution to a prolyl residue or substitution involving one of the residue in contact with the heme group, in the interior of the molecule or at the $\alpha^{1} \beta^{1}$ contact.

4. Hemoglobinopathies with erythrocytosis. Abnormal hemoglobins causing erythrocytosis are characteristically due to amino acid substitutions involving one of the residues at the $\alpha^{1} \beta^{2}$ contact or around the C-terminal of the $\beta$ chain, both of which are important for the transmission of hemeheme interaction.

We determined the oxygen equilibrium of red cell carrying $\mathrm{Hb}$ Bethesda, $\alpha_{2} \beta_{2}{ }^{145 \mathrm{Tyr}}$ $\rightarrow$ His, hemolysate and isolated $\mathrm{Hb}$ Bethesda, by use of the automatic recording apparatus, which was devised in our laboratory. As shown in Fig. 2, Hb Bethesda had a raised oxygen affinity accompanied by a diminished heme-heme interaction. These functional abnormalities may lead the peripheral tissues to hypoxia and induce the erythropoiesis by way of the secretion of erythropoietin.

It is quite worthy of note that there are also many abnormal hemoglobins which are not associated with any disease or symptom. It should be pointed out that in these variants the replacement of amino acid residues is generally on the surface of the hemoglobin molecule.

Molecular pathology of human hemoglobins deduced from investigations of the hemoglobinopathies is summarized in Table 2.

It is intriguing that the molecular biol- 


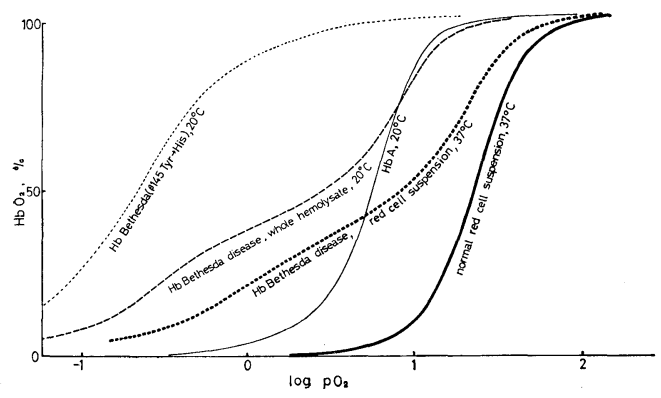

Fig. 2. Oxygen equilibrium curves of red cell suspension containing hemoglobin Bethesda and A, whole hemolysate and purified hemoglo. bin Bethesda.

The curves for normal red cell suspension and hemoglobin A separated from hemoglobin Bethesda are also shown for comparison.

Oxygen equilibruim curves were measured using a automatic recording aparatus. The curves for red cell suspension were measured in isotonic phosphate buffer, pH 7.4, at $37^{\circ} \mathrm{C}$. The curves for whole hemolysate and purified hemoglobins were done in $0.1 \mathrm{M}$ phosphate buffer, $\mathrm{pH} 7.4$, at $20^{\circ} \mathrm{C}$.

ogy of gene action worked out in microorganism can explain the genetic mechanism leading to the production of abnormal hemoglobins without any controversy. The relations of changes in the primary structure of hemoglobin to genetic alterations are outlined in Table 3 .
Table 2. Molecular pathology of human hemoglobins.

\begin{tabular}{ll}
\hline Replacements or deletions & Clinical manifestations \\
\hline surface & none \\
internal & hemolytic anemia \\
contacts between subunits & \\
$\alpha^{1} \beta^{1}$ & hemolytic anemia \\
$\alpha^{1} \beta^{2}$ & erythrocytosis \\
around C terminal & erythrocytosis \\
heme contact groups & $\begin{array}{l}\text { cyanosis } \\
\text { hemolytic anemia }\end{array}$ \\
others & $\begin{array}{l}\text { sickled rèd cells } \\
\text { hemolytic anemia }\end{array}$ \\
\hline
\end{tabular}

Molecular diseases defined above are, of course, not confined to hemoglobin. An increasing number of molecular diseases is reported, including glucose-6-phosphate dehydrogenase, fibrinogen, thrombin, plasma lipoproteins and so on. In the Lesch-Nyhan syndrome which was originally reported to be deficient in hypoxanthine-guanine phosphoribosyl transferase, a variant enzyme immunologically different from normal one has recently been demonstrated. On the other hand, even in the absence of an enzyme variant, such as sucrase-isomaltase deficiency, a major mutation of the structural gene should be kept in mind. In such instances, the hemoglobinopathies would be an excellent model for the elucidation of

Table 3. Relationship between genetic and structural abnormalities in bbnormal hemoglobins.

\begin{tabular}{|c|c|c|}
\hline Genetic alteration & $\begin{array}{l}\text { Gene expression in the primary. } \\
\text { structure of hemoglobin }\end{array}$ & Examples \\
\hline \multirow{3}{*}{ point mutation } & an amino acid substitution & $\begin{array}{l}\text { Hb M Boston } \\
\alpha 58 \text { His } \rightarrow \text { Tyr }\end{array}$ \\
\hline & an elongated chain & $\begin{array}{l}\text { Hb Constant Spring } \\
\alpha 142 \text { Gln }-172 \text { Glu }\end{array}$ \\
\hline & a shortened chain & $\begin{array}{l}\text { Hb Mckees Rocks } \\
\beta 145 \text { Tyr - Term }\end{array}$ \\
\hline \multirow{3}{*}{ crossing over } & $\begin{array}{l}\text { deletion of amino acid } \\
\text { residue(s) }\end{array}$ & $\begin{array}{l}\text { Hb Gun Hill } \\
\text { B } 92 \text { His - } 96 \text { Leu deletion }\end{array}$ \\
\hline & insertion of amino acid(s) & $\begin{array}{l}\text { Hb Grady } \\
\text { B } 116 \text { Glu }-118 \text { Thr insertion }\end{array}$ \\
\hline & fusion of $\beta$ and $\delta$ chains & $\begin{array}{l}\text { Hb Lepore } \alpha_{2}(\delta \beta)_{2} \\
\text { Hb Miyada } \alpha_{2}(\beta \delta)_{2}^{2}\end{array}$ \\
\hline frame-shift mutation & $\begin{array}{l}\text { sequential substitutions of } \\
\text { amino acid residue(s) and } \\
\text { elongation of a chain }\end{array}$ & $\begin{array}{l}\text { Hb Wayne } \\
\alpha 139 \text { Asn - } 146 \text { Arg }\end{array}$ \\
\hline $\begin{array}{l}\text { point mutations at two } \\
\text { different sites, or } \\
\text { point mutation and } \\
\text { intragenic crossing } \\
\text { over }\end{array}$ & $\begin{array}{l}\text { two separate amino acid } \\
\text { substitutions }\end{array}$ & $\begin{array}{l}\text { Hb C Harlem } \\
\text { B } 6 \text { Glu } \rightarrow \text { Val } \\
\text { B } 73 \text { Asp } \rightarrow \text { Asn }\end{array}$ \\
\hline
\end{tabular}


genetic heterogeneity of human enzymes.

The knowledge of molecular diseases might further be applicable to the metabolic diseases in general as well as the inborn errors of metabolism since the liabilities of certain individuals to certain diseases always have genetic background. It should be realized that the study of genetic backgrounds is very important for the understanding of etiology, pathophysiology and prevention of the diseases. The concept of molecular disease will contribute greatly to medicine in future. 